\title{
Valve-sparing root reimplantation and leaflet repair in a bicuspid aortic valve: Comparison with the 3-cusp David procedure
}

\author{
Joseph E. Bavaria, MD, Nimesh Desai, MD, PhD, Wilson Y. Szeto, MD, Caroline Komlo, BS, \\ Tyler Rhode, BA, Tyler Wallen, DO, and Prashanth Vallabhajosyula, MD, MS
}

\begin{abstract}
Objective: Valve-sparing root reimplantation (VSRR) in tricuspid aortic valve (TAV) patients is well established, but in bicuspid aortic valve (BAV) patients, it has been less widely adopted. We assessed whether valve type affects midterm outcomes with VSRR.
\end{abstract}

\begin{abstract}
Methods: A retrospective review was performed of 186 patients who underwent an aortic valve-sparing root reimplantation operation between 2004 and 2013. Of these, 129 patients underwent elective VSRR with the David V technique. Outcomes were compared in this cohort by valve type: TAV $(n=89)$ versus BAV $(n=40)$.

Results: Demographics were similar in the 2 groups. BAV patients had a higher degree of aortic insufficiency (AI) at presentation $(P<.05)$, and an enlarged preoperative annulus ( $30 \pm 4$ vs $28 \pm 6 \mathrm{~mm}, P=.06)$. All BAV patients required primary leaflet repair $(6 \%$ in the TAV group; $P<.01)$. Postoperative mortality $(0)$, stroke $(0 \%$ vs $1 \%)$, and pacemaker requirement $(0 \%$ vs $5 \%)$ were similar. Postoperative freedom from AI grade $\geq 2+$ was $100 \%$ in the entire cohort, and transvalvular gradients were similar. At follow-up, a 1-year echocardiogram showed higher peak and mean transvalvular gradients in the BAV group $(P<.01)$. One TAV group patient died from an unknown cause. The 5-year actuarial freedom from aortic valve reoperation was $100 \%$ versus $97 \% \pm 3 \%(P=.6)$. Three patients in the entire cohort have had AI grade $>2+$ on follow-up $(\mathrm{n}=1$ in the BAV group; $\mathrm{n}=2$ in the TAV group).
\end{abstract}

Conclusions: Even though BAV patients present with higher AI grade and require concomitant primary valve repair, the VSRR David V technique offers excellent midterm outcomes with both the BAV and TAV valve types. (J Thorac Cardiovasc Surg 2015;149:S22-8)

See related commentary on pages S28-9.

The efficacy and durability of the valve-sparing root reimplantation (VSRR) procedure (David V technique) for aortic root aneurysms in patients with tricuspid aortic valve (TAV) is well established. ${ }^{1-3}$ As several high-volume aortic surgery centers perform this procedure with improved outcomes, adoption of VSRR in the context of bicuspid aortic root pathology is being increasingly undertaken for a cohort of young patients. ${ }^{4-6}$ Unlike tricuspid aortic pathology, bicuspid aortic root pathology is typically accompanied by valve leaflet pathology that requires complex leaflet repair. ${ }^{7-9}$ Whereas the aortic insufficiency (AI) in TAV patients is due primarily to

From the University of Pennsylvania, Philadelphia, Pa.

Disclosures: Authors have nothing to disclose with regard to commercial support.

Read at The American Association for Thoracic Surgery Aortic Symposium, New York, New York, April 24-25, 2014.

Received for publication July 31, 2014; revisions received Oct 22, 2014; accepted for publication Oct 26, 2014; available ahead of print Dec 9, 2014.

Address for reprints: Joseph E. Bavaria, MD, Brooke Roberts-William Maul Measey Professor of Surgery Vice Chief, Division of Cardiovascular Surgery Director, Thoracic Aortic Surgery Program 6 Silverstein Pavilion, 3400 Spruce Street, Philadelphia, PA 19104 (E-mail: joseph.bavaria@uphs.upenn.edu).

0022-5223/\$36.00

Copyright $(2) 2015$ by The American Association for Thoracic Surgery

http://dx.doi.org/10.1016/j.jtcvs.2014.10.103 aneurysmal dilatation, bicuspid aortic valve (BAV) AI associated with root aneurysm is typically a combination of aneurysmal and primary leaflet pathology. Pioneering work by Boodhwani and colleagues, ${ }^{7}$ de Kerchove and colleagues, ${ }^{10}$ and Navarra and colleagues ${ }^{11}$ has shown that primary valve repair with VSRR can be safely performed in BAV patients, with excellent midterm outcomes.

Our institution has primarily adopted many of the leaflet repair techniques for BAV pathology, as advocated by Boodhwani and colleagues, ${ }^{7,8}$ and de Kerchove and colleagues, ${ }^{10}$ although important differences remain in the VSRR techniques employed in the reimplantation of the aortic neoroot. ${ }^{4}$ As we have become increasingly more comfortable with BAV primary leaflet repair with VSRR in patients presenting with aortic root aneurysm, in this report, we compare our institutional outcomes with VSRR, based on the aortic valve type: BAV versus TAV.

\section{MATERIALS AND METHODS Patient Population}

The institutional review board of the University of Pennsylvania approved the study and waived the need for patient consent. From 2004 to 2013, 186 patients underwent VSRR: 146 patients had tricuspid aortic valve; and 40 patients had bicuspid aortic valve (BAV group). A total of 89 patients with TAV underwent elective VSRR with the David V technique (TAV group). Patient demographics were similar overall, with a mean patient age of around 46 years. Data were prospectively maintained. 

Abbreviations and Acronyms
$\mathrm{AI}=$ aortic insufficiency
$\mathrm{BAV}=$ bicuspid aortic valve
$\mathrm{LV}=$ left ventricular
PTFE = polytetrafluoroethylene
$\mathrm{TAV}=$ tricuspid aortic valve
VSRR $=$ valve-sparing root reimplantation

\section{Anatomic Features of BAV and TAV}

All patients in the BAV group had a conjoint cusp, with a fusion occurring between the right and left or between the right and noncoronary leaflets. The majority ( $94 \%$ ) of patients presented with $\geq 2+$ AI. In total, 93 patients $(72 \%)$ required transverse aortic hemiarch reconstruction under circulatory arrest. The TAV-group patients all had tricuspid aortic valve, with $53 \%$ of patients having Marfan syndrome $(n=47)$ (Figure 1$)$. The TAV group had a lower rate of preoperative AI grade $\geq 2+$, compared with the BAV group (Table 1).

\section{Surgical Technique}

Valve evaluation and cusp repair. The BAV or TAV was evaluated in its native state, and repair was completed first with aortic root intact. The repaired valve was reassessed after completion of reimplantation. Techniques of primary cusp repair have been well described. Fenestrations were either left alone, repaired primarily, or treated with free-margin shortening of the entire leaflet using polytetrafluoroethylene (PTFE) (the type of PTFE was Gore-Tex, a registered trademark of W. L. Gore \& Associates, Inc, Flagstaff, Ariz). In the BAV group, raphe release or resection with primary closure was performed in most patients $(n=39 ; 98 \%)$ (Table 2). Leaflet repair included leaflet plication and or resection, leaflet decalcification, and fenestration closure, with plication being the most common technique $(\mathrm{n}=36$; $90 \%$ ). Patch repair was not performed in any of the cases. In the entire cohort, 6 patients $(7 \%)$ required PTFE (Gore-Tex) stitch free-margin shortening for cusp fenestrations that occurred toward the middle of the pathologic leaflet.

Root reimplantation. In the $\mathrm{BAV}$ group, the repaired $\mathrm{BAV}$ was evaluated for the relation between the conjoint and nonconjoint cusps. If the nonconjoint cusp occupied $\geq 170^{\circ}$ of the annulus perimeter at the leaflet insertion site, and this corresponded to the surface area that the cusp occupied at the annular plane, then root reimplantation was performed at a $180^{\circ} / 180^{\circ}$ orientation, with each leaflet occupying equal surface area. If the repaired BAV in its native root was closer to a "typical" type I BAV (the conjoint cusp occupies 7/12 of the leaflet insertion site and cusp surface area at the annular plane; the nonconjoint cusp occupies 5/ 12 of the perimeter and cusp surface area), then the reimplantation was performed at a $150^{\circ} / 210^{\circ}$ orientation. These techniques are described elsewhere. ${ }^{4}$

In the TAV group, the tricuspid valve was always oriented in a geometrically symmetrical $120^{\circ}$-per-leaflet orientation. TAV VSRR (David V technique) is described elsewhere. ${ }^{12}$ In $93 \%$ of VSRR cases using the David V technique, the GelweaveValsalva graft (Vascutek Ltd, Renfrewshire, Scotland) was used for reimplantation.

Aortic hemiarch replacement. In patients with ascending aorta and sinotubular junction aneurysmal dilatation that met surgical criteria for more distal resection, ascending aorta with transverse hemiarch reconstruction was performed in addition. Open distal aortic reconstruction with either retrograde cerebral perfusion under deep hypothermic circulatory arrest or antegrade cerebral perfusion under moderate hypothermic circulatory arrest was performed in all cases of distal ascending aorta replacement (Table 2).

\section{Echocardiography}

Intraoperative transesophageal echocardiography was performed preand post-procedure in all cases. Intraoperative echo guided and confirmed decisions regarding techniques for repair and root stabilization. Echocardiography was performed in all cases to evaluate for the presence of residual AI, and its orientation and degree. Coaptation height was assessed, with a goal of a $\geq 5$-mm coaptation zone postreimplantation. Any residual AI grade $>1+$ mandated re-exploration of the aortic valve.

\section{Patient Follow-up}

All patients underwent transthoracic echocardiography at discharge. Patients were followed up in clinic at 1 month postoperatively, and at least every 6 months thereafter for the first 2 years, and yearly thereafter. If patients did not have new onset of symptoms, or changes on exam, echo was performed on a yearly basis. Clinical and echocardiographic follow-up have remained at $100 \%$ and $97 \%$, respectively.

\section{Statistical Analysis}

All continuous variables are expressed as mean \pm standard deviation. Univariate analysis was performed with the Fisher exact test to compare categoric variables, and the Student $t$ test and analysis of variance to compare continuous variables. Statistical methods were applied to compare freedom from reintervention and late survival using Kaplan-Meier curves. SPSS software, version 19.0 (SPSS, Inc, Chicago, Ill) was used for all calculations.

\section{RESULTS}

\section{Preoperative and Intraoperative Outcomes}

Follow-up totaled 657 patient years, with an average of 5.1 years for the entire cohort. Overall, this was a young cohort of patients, with a mean age of $45 \pm 13$ years; $76 \%(n=98)$ of the patients were men. The comorbid burden was similar in the 2 groups (Table 1), with $>40 \%$ of patients in both groups presenting with greater than Class II New York Heart Association heart failure. The BAV group had enlarged left ventricular (LV) end diastolic diameter $(57 \pm 10 \mathrm{~mm})$ compared with the TAV group (53 $\pm 7 \mathrm{~mm}, P<.01$ ), and the mean preoperative aortic annular diameters were $30 \pm 4 \mathrm{~mm}$ and $28 \pm 6$ $\mathrm{mm}$ in the BAV and TAV groups, respectively. Aortic root and ascending aorta dimensions were similar in the 2 groups. Preoperative AI grade $\geq 2+$ at presentation was more frequent in the BAV group $(n=38$ [95\%] vs $\mathrm{n}=48(54 \%) ; P<.01)$.

Intraoperative times were similar in the 2 groups (Table 2). The majority of the cohort required transverse hemiarch replacement under circulatory arrest for ascending aortic aneurysm. In the TAV group, $6 \%$ $(n=5)$ of the patients required concomitant mitral valve intervention (all were Marfan patients), compared with none in the BAV group. An important difference between the 2 groups was the primary leaflet repair rates $(100 \%$ in the BAV group vs $7 \%$ in the TAV group; $P<.01$ ) (Table 2). The majority of BAV patients $(90 \%)$ underwent 


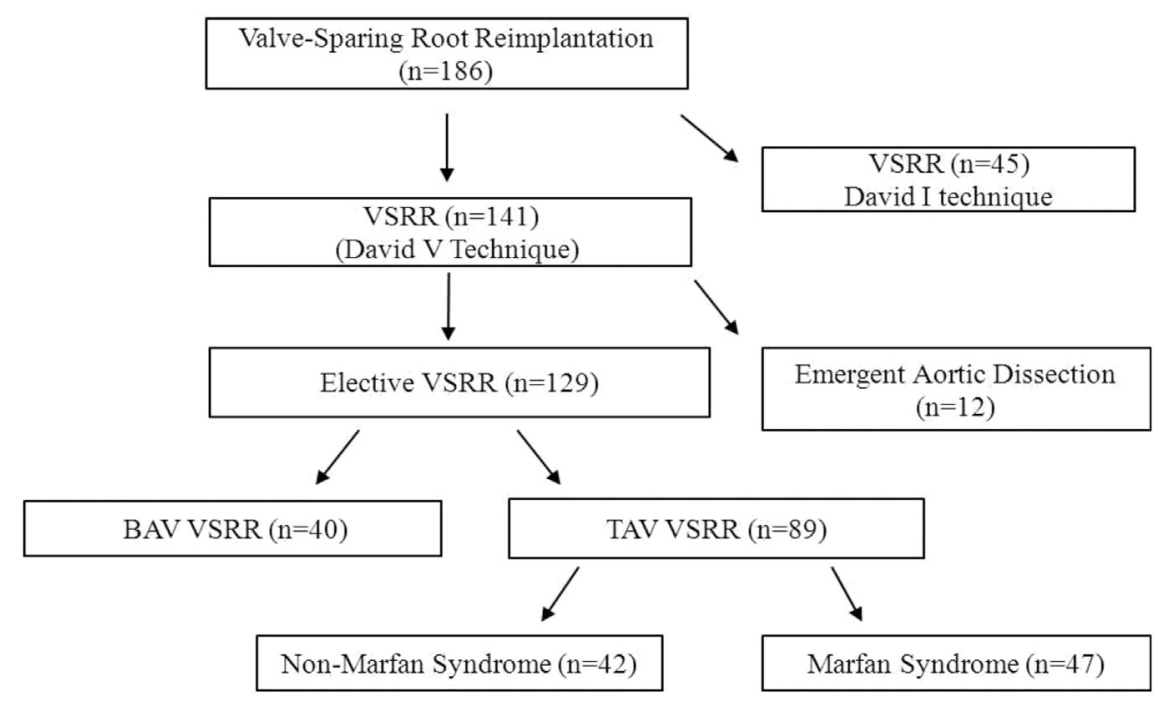

FIGURE 1. The breakdown of the valve-sparing root reimplantation patient population by subgroups. VSRR, Valve-sparing root reimplantation; $B A V$, bicuspid aortic valve; $T A V$, tricuspid aortic valve.

leaflet plication, compared with only $2 \%$ in the TAV group $(P<.01)$.

\section{Postoperative Outcomes}

To date, postoperative mortality has remained at zero in the entire cohort (Table 3), and stroke rates have remained very low $(0 \%$ vs $1 \%)$. Although differences between the 2 groups were not significant, the pacemaker rate $(0 \%$ vs $5 \%[\mathrm{n}=4])$, and the rate of reoperation for bleeding $(0 \%$ vs $7 \%[n=6])$ were slightly higher in the TAV group. There

TABLE 1. Preoperative demographics and aortic parameters

\begin{tabular}{lccc}
\hline \multicolumn{1}{c}{ Demographics } & BAV & TAV & $P$ value \\
\hline $\mathrm{N}$ & 40 & 89 & \\
Age (y) & $46 \pm 12$ & $45 \pm 15$ & .7 \\
Sex (men:women) & $35: 5$ & $63: 26$ & .3 \\
Hypertension (n [\%]) & $17(43)$ & $52(58)$ & .1 \\
Diabetes (n [\%]) & $5(13)$ & $4(4)$ & .1 \\
Smoker (n [\%]) & $13(33)$ & $36(40)$ & .4 \\
Class II NYHA (n [\%]) & $16(40)$ & $38(43)$ & .8 \\
Ejection fraction (\%) & $58 \pm 9$ & $56 \pm 10$ & .3 \\
LV diastolic diameter (mm) & $57 \pm 10$ & $53 \pm 7$ & .01 \\
LV systolic diameter (mm) & $37 \pm 8$ & $35 \pm 7$ & .2 \\
Annulus (mm) & $30 \pm 4$ & $28 \pm 6$ & .06 \\
Sinotubular junction (mm) & $43 \pm 6$ & $44 \pm 7$ & .4 \\
Sinus of Valsalva (mm) & $52 \pm 5$ & $52 \pm 5$ & 1.0 \\
Ascending aorta (mm) & $46 \pm 10$ & $46 \pm 10$ & 1.0 \\
Preoperative aortic insufficiency (n [\%]) & & & $<.01 *$ \\
$\quad 0$ & $1(3)$ & $23(26)$ & \\
1 & $1(3)$ & $18(20)$ & \\
2 & $15(38)$ & $23(26)$ & \\
3 & $9(23)$ & $11(12)$ & \\
4 & $14(35)$ & $14(16)$ & \\
\hline BAV, Bing
\end{tabular}

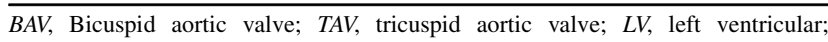
$N Y H A$, New York Heart Association. *Overall $P$ value of $\chi^{2}$ analysis of preoperative aortic insufficiency grades. has been no case with residual AI grade $>1+$ in the early postoperative period. Postoperative peak and mean gradients were similar in the 2 groups (Table 3). Leaflet coaptation height was similar in the 2 groups, even though all the BAV patients required primary leaflet repair: $9 \pm 2 \mathrm{~mm}$ versus $8 \pm 2 \mathrm{~mm}(P<.01)$.

\section{Follow-up Outcomes}

All patients have had clinical follow-up, and $97 \%$ have had $\geq 1$ postoperative echocardiogram. In the entire cohort, 1 death from unknown cause has occurred in a TAV-group patient (Figure 2, A). No significant differences were found between the TAV and BAV groups in the aortic valve failure

TABLE 2. Intraoperative parameters

\begin{tabular}{lccc}
\hline \multicolumn{1}{c}{ Parameters } & BAV & TAV & P value \\
\hline N & 40 & 89 & \\
Cardiopulmonary bypass (min) & $292 \pm 58$ & $277 \pm 50$ & .1 \\
Cross clamp (min) & $241 \pm 51$ & $231 \pm 39$ & .2 \\
Circulatory arrest (min) & $19 \pm 5$ & $18 \pm 5$ & .3 \\
Arch replacement (n [\%]) & $28(70)$ & $65(73)$ & .8 \\
Mitral valve repair (n [\%]) & 0 & $5(6)$ & .3 \\
Coronary artery bypass graft (n [\%]) & $1(3)$ & $3(3)$ & 1.0 \\
Leaflet repair techniques (n [\%]) & & & \\
$\quad$ Primary leaflet repair & $40(100)$ & $6(7)$ & $<.01$ \\
Raphe release & $34(85)$ & $\mathrm{N} / \mathrm{A}$ & \\
$\quad$ Resection with primary closure & $5(13)$ & $\mathrm{N} / \mathrm{A}$ & \\
PTFE* free-margin shortening & $3(8)$ & $3(3)$ & .4 \\
Leaflet plication & $36(90)$ & $2(2)$ & $<.01$ \\
Leaflet decalcification & $5(13)$ & 0 & $<.01$ \\
Patch repair & 0 & 0 & 0 \\
Fenestration repair & $5(13)$ & $2(2)$ & .03 \\
\hline BAV, Bict
\end{tabular}

$B A V$, Bicuspid aortic valve; $T A V$, tricuspid aortic valve; $N / A$, not applicable; PTFE, polytetrafluoroethylene. *The type of PTFE was Gore-Tex, a registered trademark of W. L. Gore \& Associates, Inc, Flagstaff, Ariz. 
TABLE 3. Patient outcomes: Postoperative outcomes and discharge echocardiography parameters; and 1-year echocardiogram follow-up parameters

\begin{tabular}{lccc}
\hline \multicolumn{1}{c}{ Parameters } & BAV & TAV & $P$ valu \\
\hline Postoperative outcomes and discharge echocardiography & \\
N & 40 & 89 & \\
Reoperation for bleeding & 0 & $6[7]$ & .2 \\
$\quad$ (n [\%]) & & & \\
Pacemaker placement & 0 & $4[5]$ & .3 \\
$\quad$ (n [\%]) & & & \\
Mortality (n [\%]) & 0 & 0 & 1.0 \\
Stroke (n [\%]) & 0 & $1[1]$ & 1.0 \\
Freedom from AI grade & $40[100]$ & $89[100]$ & 1.0 \\
$\quad>1+(n$ [\%]) & & & \\
Peak gradient (mm Hg) & $12 \pm 6$ & $12 \pm 7$ & 1.0 \\
Mean gradient (mm Hg) & $6 \pm 3$ & $6 \pm 4$ & 1.0 \\
Leaflet coaptation (mm) & $9 \pm 2$ & $8 \pm 2$ & $<.01$ \\
1-y echocardiogram follow-up & & & \\
N $\quad 22$ & 54 & \\
Peak gradient (mm Hg) & $15 \pm 4(15 / 22)$ & $10 \pm 5(17 / 54)$ & $<.01$ \\
Mean gradient (mm Hg) & $8 \pm 2(14 / 22)$ & $5 \pm 3(14 / 54)$ & $<.01$ \\
Ejection fraction (\%) & $60 \pm 9(22 / 22)$ & $58 \pm 7(54 / 54)$ & .3 \\
LV diastolic dimension & $50 \pm 8(21 / 22)$ & $51 \pm 8(54 / 54)$ & .6 \\
$\quad$ (mm) & & & .1 \\
LV systolic dimension & $32 \pm 7(21 / 22)$ & $35 \pm 8(49 / 54)$ & \\
$\quad$ (mm) & & & \\
\hline
\end{tabular}

Parentheses represent the number of data points analyzed for each echo parameter. $B A V$, Bicuspid aortic valve; $T A V$, tricuspid aortic valve; $A I$, aortic insufficiency; $L V$, left ventricular.

rates over midterm follow-up (Figure 2, $B$ ). Actuarial 5-year survival was $99 \% \pm 1 \%$ in the entire cohort (Figure $2, A$ ). Overall actuarial freedom from aortic valve reoperation for structural valve deterioration was $98 \% \pm 2 \%$ at 5 years (Figure 2,B). Three patients in the entire cohort have had AI grade $>2+$ on follow-up $(\mathrm{n}=1$ in the BAV group; $\mathrm{n}=2$ in the TAV group). All of these patients had AI 1+ at discharge echocardiography. We are currently following these patients, as they have not had any major symptomatology yet, and the LV diameters and ejection fraction are within normal limits.

At the 1-year echocardiogram follow-up, LV remodeling was more prominent in BAV patients than in TAV patients, an expected difference, given the greater incidence of preoperative $\mathrm{AI}$ and $\mathrm{LV}$ dilation in $\mathrm{BAV}$ patients (Figure 3). In addition, we evaluated valvular function in patients who had a 1-year echocardiogram (Table 3). Mean LV diastolic and systolic diameters were normal in both the BAV and TAV groups. At 1 year, the peak $(15 \pm 4 \mathrm{~mm} \mathrm{Hg}, 10 \pm 5 \mathrm{~mm} \mathrm{Hg}, P<.01)$ and mean $(8 \pm 2 \mathrm{~mm} \mathrm{Hg} ; 5 \pm 3 \mathrm{~mm} \mathrm{Hg}, P<.01)$ gradient values were higher in the BAV group than in the TAV group. Compared with the postoperative discharge gradient values, the peak $(11 \pm 5 \mathrm{~mm} \mathrm{Hg}$ to $15 \pm 4 \mathrm{~mm} \mathrm{Hg})$ and mean $(5 \pm 3 \mathrm{~mm} \mathrm{Hg}$ to $8 \pm 2 \mathrm{~mm} \mathrm{Hg}$ ) gradients increased in the BAV group $(P<.01)$, but remained essentially stable in the TAV group. No differences were seen between the Marfan and non-Marfan TAV patients.

\section{DISCUSSION}

Several major institutions have reported good midterm and long-term outcomes with the VSRR procedure. VSRR is an attractive surgical option for young patients presenting with aortic root aneurysm $\pm \mathrm{AI}$, without aortic stenosis. David and colleagues ${ }^{13}$ reported freedom from aortic reoperation at 10 years for $95 \%$ of patients, with freedom from severe AI for $85 \%$ at 10 years. de Kerchove and colleagues ${ }^{14}$ reported long-term outcomes with VSRR and root-remodeling procedures. Freedom from aortic valve reoperation was at $90 \%$ at 8 years, and was similar in groups undergoing aortic valve repair versus no primary cusp repair. ${ }^{14}$ Freedom from recurrent severe AI was at $83 \%$ at 8 years. Aicher and colleagues ${ }^{15}$ reported outcomes with root remodeling in BAV and TAV patients. Freedom from severe $\mathrm{AI}$ at 5 years was at $88 \%$ in TAV patients, and $96 \%$ in BAV patients. Stephens and colleagues ${ }^{16}$ reported a $43 \%$ incidence of mild $\mathrm{AI}$ in patients undergoing VSRR with at least 1 year follow-up; $5 \%$ had moderate AI, and $2 \%$ had severe AI. A large percentage of patients with mild AI at 1 year did not progress to moderate or severe recurrent $\mathrm{AI}$ in this series. Regardless of these excellent midterm and long-term outcomes reported by these institutions, VSRR, especially in conjunction with primary aortic valve repair, remains a challenging surgical exercise.

In this study, we analyzed our institutional experience with elective VSRR, in BAV and TAV patients, utilizing the David V technique. Overall, our midterm outcomes with VSRR are similar to those reported by other major centers. ${ }^{2,3,10,17}$ So far, 1 patient in the TAV group required aortic valve reoperation for endocarditis. Further analysis of the TAV patients showed no significant differences for recurrent AI grade $>2+$ in Marfan versus non-Marfan patients. Long-term follow-up of our David $\mathrm{V}$ technique in the VSRR cohort is needed to further validate the efficacy of this procedure as compared with other aortic root procedures, such as root remodeling and Bentall root replacement.

One of the stark differences between the BAV and TAV groups was the need for primary leaflet repair in the former group (Table 2). All BAV patients required some form of leaflet repair, with the majority $(90 \%)$ undergoing leaflet plication. As routine practice, in addition to leaflet repair, we perform raphe release on the majority of type I BAV cases. Only $7 \%$ of the TAV patients underwent primary leaflet repair $(P<.01)$. Initially, we performed primary leaflet repair before root reimplantation, but now we perform valve repair after the reimplantation into the neoroot. In BAV cases, raphe release for type I BAV is performed before reimplantation. Leaflet repair had no significant effect on recurrent AI grade $>2+$ at midterm 


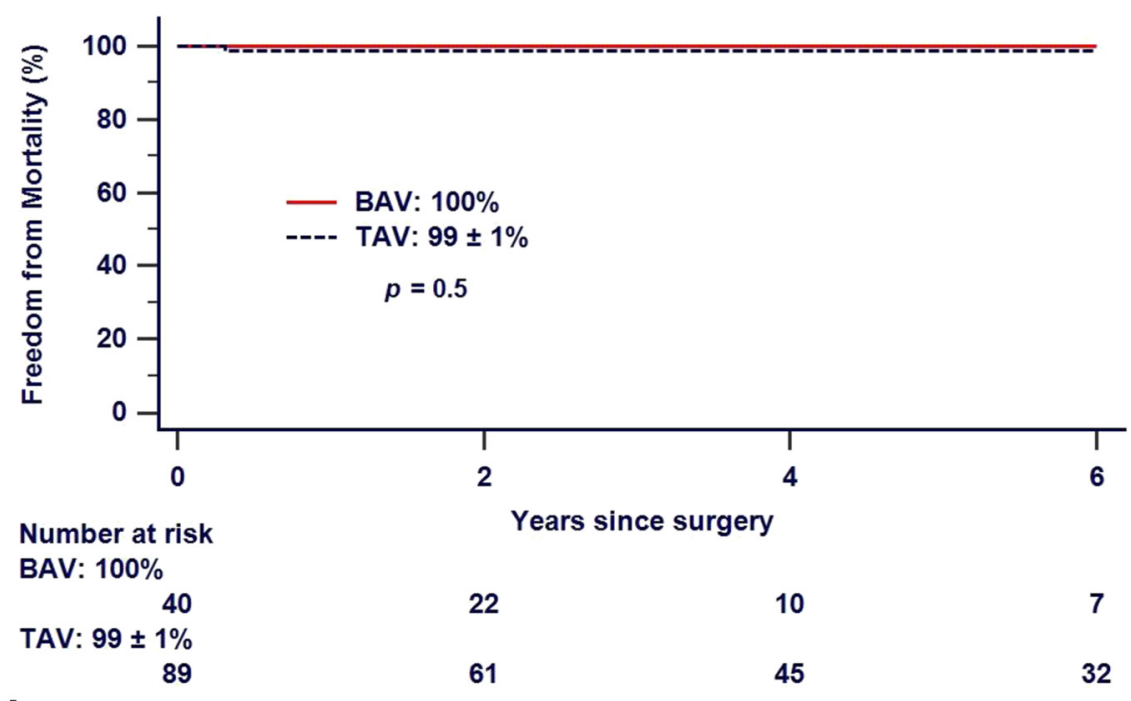

A

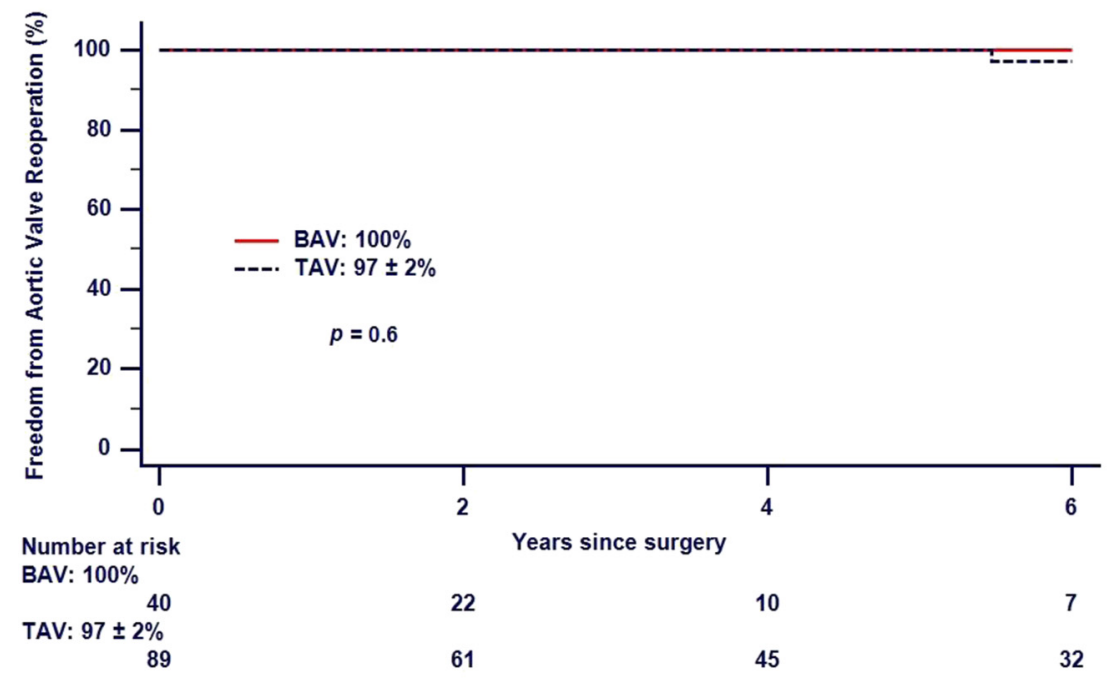

B

FIGURE 2. Kaplan-Meier curves are shown comparing BAV with TAV graphs for: (A) mortality; (B) freedom from aortic valve reoperation. BAV, Bicuspid aortic valve; $T A V$, tricuspid aortic valve.

follow-up, as only 1 patient in the BAV group developed AI grade $>2+$ on follow-up. de Kerchove and colleagues ${ }^{14}$ similarly noted that primary valve repair in the context of VSRR did not affect recurrent AI on midterm outcomes.

The leaflet-repair techniques used by the respective institutions reporting their outcomes with the VSRR procedure had differences. Navarra and colleagues ${ }^{11}$ and de Kerchove and colleagues ${ }^{14}$ report performing leaflet resuspension with PTFE (the type of PTFE was Gore-Tex, a registered trademark of W. L. Gore \& Associates, Inc, Flagstaff, Ariz) in $\sim 30 \%$ of the repaired valves, followed by central plication $(\sim 24 \%)$. Stephens and colleagues ${ }^{16}$ primarily utilized PTFE (Gore-Tex) free-margin shortening as the technique of choice in the majority of patients requiring primary valve repair. As an institutional practice, we have avoided pericardial patch repair or triangular leaflet resection as repair techniques, and instead rely primarily on simple leaflet plication for free-margin equalization as the repair technique of choice (Table 2).

This technique leaves minimal suture material on the valve leaflet, and allows multiple adjustments to be made with the addition or removal of plication sutures. For short, single fenestrations, we either perform primary repair of the leaflet at the fenestration site, or in cases of less-thanmoderate preoperative AI, we leave the fenestration alone. In cases of multiple fenestrations or a single long $(>1 / 3$ free-margin length) fenestration along a leaflet, we perform PTFE (Gore-Tex) free-margin shortening of the leaflet. 


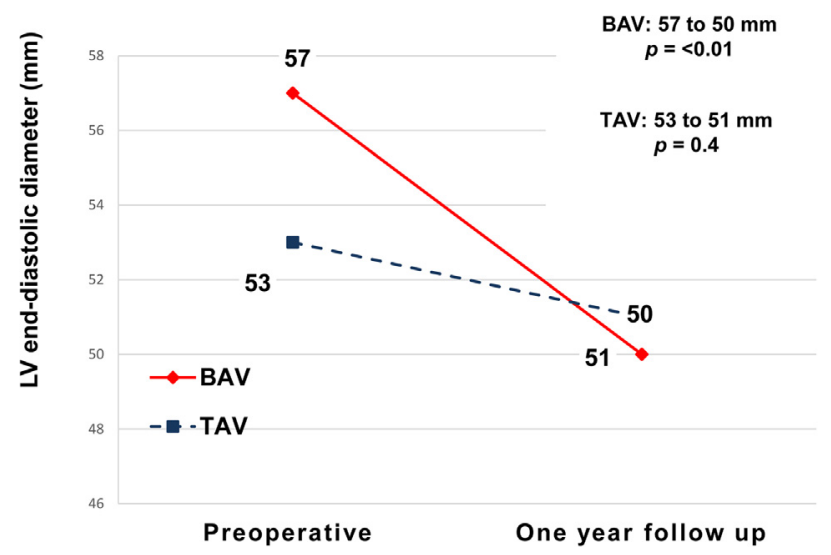

FIGURE 3. LV remodeling was assessed in patients with 1-year echocardiogram follow-up after VSRR. LV end diastolic diameter change is shown. $L V$, Left ventricular; $B A V$, bicuspid aortic valve; $T A V$, tricuspid aortic valve.

Our goal is to leave as little suture material on the aortic leaflets as possible while still achieving a successful primary valve repair. We aim to achieve a coaptation zone of $\geq 5 \mathrm{~mm}$ (mean leaflet coaptation was $8 \pm 2 \mathrm{~mm}$; Table 3). Overall, our results with VSRR provide evidence that the select patients who require concomitant primary leaflet repair are not at greater risk for higher recurrent AI at midterm follow-up. These outcomes are in accordance with the results reported by other major institutions. ${ }^{1,3,14,17}$

Our study attests to the idea that various leaflet repair techniques can be employed to treat primary valve pathology, with excellent midterm aortic valve durability. ${ }^{7-9,18}$ Therefore, in this way, principles of aortic valve repair seem to be similar to those reported in the mitral valve repair literature, in which various mitral valve repair techniques have been described as treatments for primary valve pathology. But in both instances, it is critical to appreciate that by the end of the procedure, the repaired valve should not have more than $1+$ insufficiency for midterm to long-term durability ${ }^{19}$; and some form of a robust annular stabilization technique (provided by VSRR in the context of a repaired aortic valve) is vital for valve durability. ${ }^{11}$

In addition to recurrent $\mathrm{AI}$, we evaluated transvalvular gradients in the 2 groups. Postoperative peak and mean gradients were similar in the BAV and TAV groups. At a 1-year echocardiogram follow-up, BAV patients developed an increase in transvalvular gradients, whereas the gradients remained stable in the TAV patients. It is unclear whether the increased gradients in BAV patients reflect the progression of the intrinsic pathology of the $\mathrm{BAV}$, or rather are a chronic inflammatory response to the foreign material introduced onto the aortic valve leaflets in the repair, or a combination of these. With such small sample numbers, such interpretation can only be speculative. It remains to be seen whether increasing transvalvular gradients have any effect on valve durability, although based on this study, these increases do not seem to have any effect on recurrent AI $>2+$, or to cause symptomatic aortic stenosis over midterm follow-up.

In a recent report on VSRR outcomes in BAV patients, a postoperative discharge peak gradient of $>20 \mathrm{~mm} \mathrm{Hg}$ was reported in 1 patient, without any reported effects of aortic stenosis. ${ }^{6}$ Given that all published studies indicate that the mode of failure in VSRR patients is primarily secondary to recurrent $\mathrm{AI},{ }^{17}$ the development of slight stenosis across repaired BAVs is unlikely to have any clinical relevance. However, further follow-up may still reveal clinical significance of the increasing transvalvular gradients in VSRR patients.

\section{Study Limitations}

This was a retrospective analysis of a prospectively maintained database of VSRR procedures performed at a single institution. The echocardiographic patient data that were obtained, especially on transvalvular gradients and aortic annular dimensions, were not complete, owing to current practices in which follow-up echocardiography on patients is typically performed by local cardiologists. Also, the VSRR procedure, especially valve-repair techniques, has evolved as our experience with the procedure, especially in BAV patients, has continued to grow. Therefore, there is some inconsistency in the techniques employed over time. This is a midterm follow-up study; therefore, longer follow-up is needed to further validate our findings.

\section{CONCLUSIONS}

Our study demonstrates that a valve-sparing root reimplantation procedure can be safely performed with excellent midterm outcomes, even in more complex cases in which primary aortic valve repair is required. There has been 1 patient death to date, attesting to the safety profile of this procedure. This study shows that similar midterm outcomes can be achieved irrespective of the type of aortic valve (BAV vs TAV) or the presence of connective tissue disorders. In summary, our experience further strengthens the growing body of literature advocating for valvesparing root reimplantation procedures in a carefully selected group of patients presenting with aortic root aneurysm with or without AI.

\section{References}

1. David TE, Armstrong S, Manlhiot C, McCrindle BW, Feindel CM. Long-term results of aortic root repair using the reimplantation technique. J Thorac Cardiovasc Surg. 2013;145:S22-5.

2. Coselli JS, Hughes MS, Green SY, Price MD, Zarda S, de la Cruz KI, et al. Valve-sparing aortic root replacement: Early and midterm outcomes in 83 patients. Ann Thorac Surg. 2014;97:1267-74.

3. Escobar Kvitting JP, Kari FA, Fischbein MP, Liang DH, Beraud A-S, Stephens EH, et al. David valve-sparing aortic root replacement: equivalent 
mid-term outcome for different valve types with or without connective tissue disorder. J Thorac Cardiovasc Surg. 2013;145:117-27.e5.

4. Vallabhajosyula P, Szeto WY, Komlo CM, Ryan LP, Wallen TJ, Gorman RC, et al. Geometric orientation of the aortic neoroot in patients with raphed bicuspid aortic valve disease undergoing primary cusp repair and a root reimplantation procedure. Eur J Cardiothorac Surg. 2013;45:174-80.

5. Kari FA, Liang DH, Escobar Kvitting JP, Stephens EH, Mitchell RS, Fischbein MP, et al. Tirone David valve-sparing aortic root replacement and cusp repair for bicuspid aortic valve disease. J Thorac Cardiovasc Surg. 2013; 145(3 Suppl):S35-40. e1-2.

6. Vallabhajosyula P, Komlo C, Szeto WY, Wallen TJ, Desai N, Bavaria JE. Root stabilization of the repaired bicuspid aortic valve: subcommissural annuloplasty versus root reimplantation. Ann Thorac Surg. 2014;97:1227-34.

7. Boodhwani M, de Kerchove L, Glineur D, Poncelet A, Rubay J, Astarci P, et al. Repair-oriented classification of aortic insufficiency: impact on surgical techniques and clinical outcomes. J Thorac Cardiovasc Surg. 2009;137:286-94.

8. Boodhwani M, de Kerchove L, Glineur D, Rubay J, Vanoverschelde JL, Noirhomme P, et al. Repair of regurgitant bicuspid aortic valves: a systematic approach. J Thorac Cardiovasc Surg. 2010;140:284.e1.

9. Boodhwani M, de Kerchove L, Glineur D, Rubay J, Vanoverschelde JL, Van Dyck M, et al. Aortic valve repair with ascending aortic aneurysms: associated lesions and adjunctive techniques. Eur J Cardiothorac Surg. 2011:40:424-8.

10. de Kerchove L, Boodhwani M, Glineur D, Vandyck M, Vanoverschelde JL, Noirhomme P, et al. Valve sparing-root replacement with the reimplantation technique to increase the durability of bicuspid aortic valve repair. $J$ Thorac Cardiovasc Surg. 2011;142:1430-8.
11. Navarra E, El Khoury G, Glineur D, Boodhwani M, Van Dyck M, Vanoverschelde JL, et al. Effect of annulus dimension and annuloplasty on bicuspid aortic valve repair. Eur J Cardiothorac Surg. 2013;44:316-23.

12. Boodhwani M, de Kerchove L, El Khoury G. Aortic root replacement using the reimplantation technique: tips and tricks. Interact CardioVasc Thorac Surg. 2009;8:584-6.

13. David TE, Feindel CM, Webb GD, Colman JM, Armstrong S, Maganti M Long-term results of aortic valve-sparing operations for aortic root aneurysm J Thorac Cardiovasc Surg. 2006;132:347-54.

14. de Kerchove L, Boodhwani M, Glineur D, Poncelet A, Verhelst R, Astarci P, et al. Effects of preoperative aortic insufficiency on outcome after aortic valve-sparing surgery. Circulation. 2009;120(11 Suppl):S120-6.

15. Aicher D, Langer F, Lausberg H, Bierbach B, Schäfers H. Aortic root remodeling: ten-year experience with 274 patients. J Thorac Cardiovasc Surg. 2007;134:909-15.

16. Stephens EH, Liang DH, Kvitting JE, Kari FA, Fischbein MP, Mitchell RS, et al. Incidence and progression of mild aortic regurgitation after Tirone David reimplantation valve-sparing aortic root replacement. J Thorac Cardiovasc Surg. 2014;147:178.e3.

17. Oka T, Okita Y, Matsumori M, Okada K, Minami H, Munakata H, et al. Aortic regurgitation after valve-sparing aortic root replacement: modes of failure. Ann Thorac Surg. 2011;92:1639-44.

18. Boodhwani M, El Khoury G. Principles of aortic valve repair. J Thorac Cardiovasc Surg. 2010;140(6 Suppl):S22.

19. Augoustides JGT, Szeto WY, Bavaria JE. Advances in aortic valve repair: focus on functional approach, clinical outcomes, and central role of echocardiography J Cardiothorac Vasc Anesth. 2010;24:1016-20.

\title{
EDITORIAL COMMENTARY
}

\section{Valve-sparing root reimplantation and bicuspid aortic valve repair: Optimism and realism}

\author{
Kevin L. Greason, MD
}

See related article on pages S22-8.

In this issue of the Journal, Bavaria and colleagues report the outcomes of aortic valve-sparing root reimplantation and leaflet repair in bicuspid and tricuspid aortic valves. Readers should find this article interesting for several reasons. The authors have provided an in-depth analysis of the aortic valve-repair groups with respect to baseline valve function, simplified methods of repair, and outcomes. The main focus of the study, however, is the bicuspid aortic valve-repair group.

From the Division of Cardiovascular Surgery, Mayo Clinic, Rochester, Minn. Disclosures: Author has nothing to disclose with regard to commercial support. Received for publication Nov 11, 2014; accepted for publication Nov 13, 2014; available ahead of print Dec 9, 2014.

Address for reprints: Kevin L. Greason, MD, Mayo Clinic, 200 First St Southwest, Rochester, MN 55905 (E-mail: greason.kevin@mayo.edu).

J Thorac Cardiovasc Surg 2015;149:S28-9

$0022-5223 / \$ 36.00$

Copyright $($ c 2015 by The American Association for Thoracic Surgery

http://dx.doi.org/10.1016/j.jtcvs.2014.11.024
This is an important paper that reports on aortic valve repair in relatively young patients. In this study, the mean age of patients was $46 \pm 12$ years in the bicuspid-aortic valve group and $45 \pm 15$ years in the tricuspid-aortic valve group. The obvious advantage of aortic valve repair in these patients in comparison with aortic valve replacement must be considered. In this age group, biological valves have limited durability; on the other hand, lifelong warfarin therapy necessitated by mechanical valves has its own set of related concerns.

The respective aortic valve-repair groups had similar baseline patient characteristics for the most part, but with a few important differences. Preoperative $\geq 2+$ aortic valve regurgitation was present in $96 \%$ of patients with a bicuspid aortic valve, but in only $54 \%$ of patients with a tricuspid aortic valve. As one would expect, the resultant left ventricular diastolic diameter was also greater in the bicuspid-aortic valve group $(57 \pm 10 \mathrm{~mm}$ vs $53 \pm 7 \mathrm{~mm}$ ).

The main operative difference in the 2 aortic valve-repair groups was the need for cusp repair. All patients (100\%) received cusp repair in the bicuspid-aortic valve group, 